\title{
Efficient and optimized design of Synchronous buck converter with feedback compensation in 130nm technology
}

\author{
${ }^{1}$ Er.Preeti Budhiraja, ${ }^{2}$ Prof.Rachna Manchanda \\ ${ }^{1,2}$ Chandigarh group of colleges Landran, Mohali, India
}

\begin{abstract}
A$ voltage regulator is a electronic circuit that maintains a constant output voltage irrespective of change in load current. With the rapid increase in circuit complexity and improved technology a more severe requirement for accurate and fast regulation is desired. This has led to need for new and more reliable design of buck converters. The buck converter inputs an unregulated dc voltage input and outputs a constant or regulated voltage. This paper discusses about efficient design of buck Converter with type 3 compensator and also gives detailed analysis on stability, steady state analysis, output ripple and Power efficiency. For investigating stability Mat-lab tool is used and system level simulation has been carried out with Cadence-P spice. With input voltage of $3 \mathrm{~V}$ and Output Voltage of $1.5 \mathrm{~V}$ with variations in load current from 100mA-500mA, optimum efficiency of $93 \%$ is obtained using $130 \mathrm{~nm}$ CMOS Technology
\end{abstract}

Index Terms: Pwm, Mosfet,regulation, ripple

\section{Introduction}

As modern digital devices are capable of operating at increasingly lower voltages $(\approx 1 \mathrm{~V})$, it has become standard to convert higher system rail voltages to low voltages at close proximity to the load. This allows for lower conduction loss through the system rails since currents will be significantly lower than the device load current. Thus, DC-DC "step-down" converters are required for this application. As implied, step-down converters convert a higher DC voltage to a lower DC voltage. For microprocessor applications (either central processing units (CPU) or graphic processing units (GPU)), these converters are often referred to as a voltage regulator modules (VRM). VRMs are responsible for converting a DC voltage (typically 12V) provided by an AC-DC rectifier (often referred to as the "silver box") to a much lower DC voltage (typically $0.8 \mathrm{~V}-1.5 \mathrm{~V}$ ) to supply the microprocessor. While there exist a large variety of DC-DC converters that could perform such a task, the synchronous Buck converter is usually employed due to its relative simplicity and low cost.[1][8]

\section{Types of buck converter}

There are basic two types of regulator-Linear regulator and Switching Regulator.

Linear regulator is a type of power supply which instead of using switches, employs voltage divider network for adjusting output voltage.

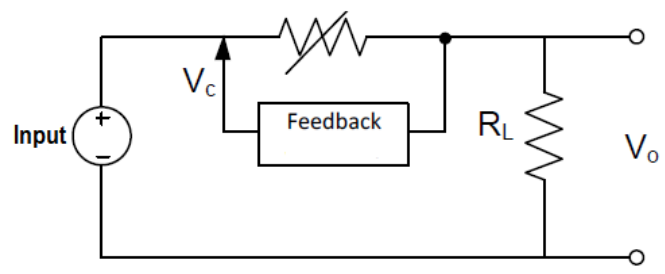

Figure.1 Linear regulator

Switching-mode power supply which is also called as switching-mode DC to DC converter is a type of power supply which uses switches (usually in the form of transistor) and low loss components such as inductors, capacitors and transformers for regulating output voltage. MOSFET is used as a power switch in SMPS for stabilizing output voltage. The switches are not conducted continuously and they operate under specific frequency, therefore they are useful for conservation of battery life and reduction of the power loss in the circuit.[2] 


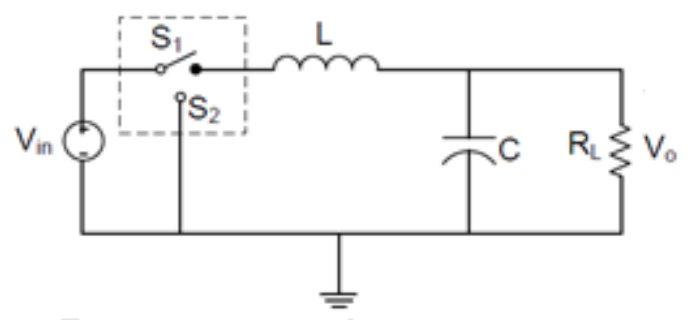

Figure.2 switching regulator

\section{Buck Converter}

Buck converter is a type of switching-mode power supply which is used for stepping-down DC voltage level. Switch controller block and power block are two main parts of buck converter's circuit. It can operate in Continuous Conduction Mode or in Discontinuous Conduction Mode, depending on the waveform of the inductor current [1]. Voltage Mode Control and Current Mode Control are two main methods to control switching. Both of these two methods can be applied with either PWM (Pulse width modulation) or PFM (pulse frequency modulation) techniques.[3][4]

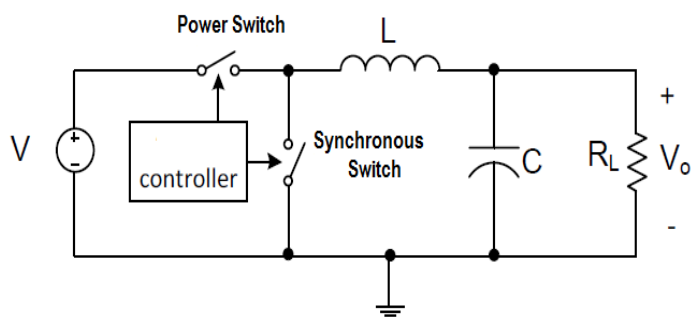

Figure.3 Buck Converter

A.) Design equations of Filter

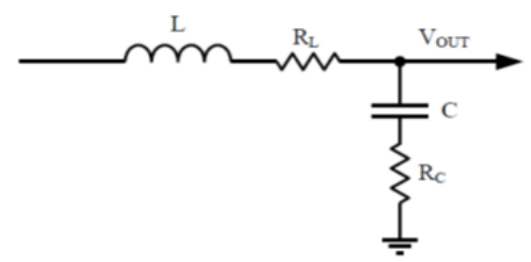

Figure.4 Basic Filter

The transfer function is calculated according to the equation

$$
\begin{gathered}
\operatorname{Gain}_{L C}=\frac{\text { Vout }}{V_{A}}=\frac{\frac{1}{s C}+R_{c}}{R_{L}+s L+\frac{1}{s C}+R_{c}}=\frac{1+s R_{c} C}{1+s\left(R_{L}+R_{c}\right)+s^{2} L C} \\
F_{Z_{\left(R_{C} C\right)}}=\frac{1}{2 \pi R_{c} C} \\
F_{P(L C)}=\frac{1}{2 \pi \sqrt{L C}}
\end{gathered}
$$

\section{Feedback Compensation}

A) Why Compensation is required:-

Basically, an open-loop DC-DC converter cannot regulate its output voltage due to varies in input voltage or changes at load. Compensator is used to overcome these problems so that the converter will produces a stable output voltage.[10] 
The compensator block is responsible for providing sufficient gain to make the output voltage very nearly equal to the reference voltage (times a constant) and sufficient phase margin so that the output voltage doesn't ring or oscillate in response to a load step.

B) Problems in Open Loop:-

B.1) Unstable Output Voltage

Basically, an open loop DC-DC converter cannot regulate its output voltage due to varies in input voltages or change at load.

B.2) Instability System

Too much or less phase margin an open loop DC-DC converter will cause the output voltage to respond too slowly to a load step, thus contribute instability condition of the system.

B.3) High Ripple and Harmonic Problem

Ripple and Harmonics that produced in open loop DC-DC converter also high thus contribute reduced in the output efficiency.

C) Types of Compensator:-

The ideal Bode plot for the compensated system would be a gain that rolls off at a slope of $-20 \mathrm{~dB} / \mathrm{decade}$, crossing $0 \mathrm{db}$ at the desired bandwidth and a phase margin greater than 45 Degree for all frequencies below the $0 \mathrm{~dB}$.

C.1) Type I Compensation-

A Type-I compensation network provides a single pole at the origin and the gain rolls off at $-20 \mathrm{~dB} / \mathrm{decade}(-1$ slope) forever, crossing unity gain at the frequency where the reactance of $C_{1}$ is equal in magnitude to the resistance of $\mathrm{R}_{1}$.

Type-I compensation network is used for systems where the phase shift of the modulator is minimal.

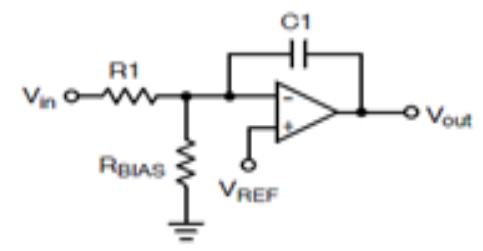

Figure.5 Type I Compensation

C.2) Type II compensation-

The compensation network of Type 2 offers improved buck converter transient response when the converter is subject to output load changes, as opposed to the slow response of the Type-I compensation network.

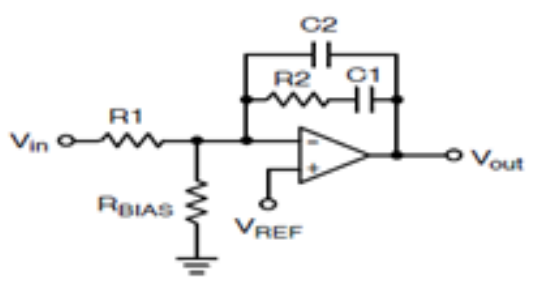

Figure.6 Type II Compensation

C.3 Type III Compensation-

The compensation network of Type III can give superior transient response. In this circuit, the network provides a pole at the origin with two zero-pole pairs. 


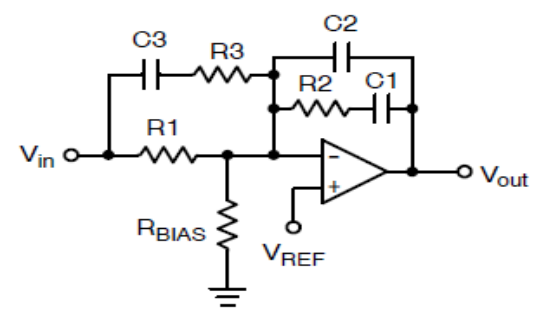

Figure.7 Type III Compensation

C.4) Why Type III Compensator for Buck regulator-

Type II compensators are widely used in the control loops for power converters. However, there are cases where the phase lag of a power converter can approach 180 degrees, while the maximal phase from a type II compensator at any frequencies is at most zero degree. Thus in these cases, the type II compensator cannot provide enough phase margin to keep the loop stable, and this is where a type III compensator is needed.

A type III compensator can have a phase plot going above zero degree at some frequencies, and therefore it can provide the required phase boost to maintain a reasonable phase margin.

C.5) Transfer function-

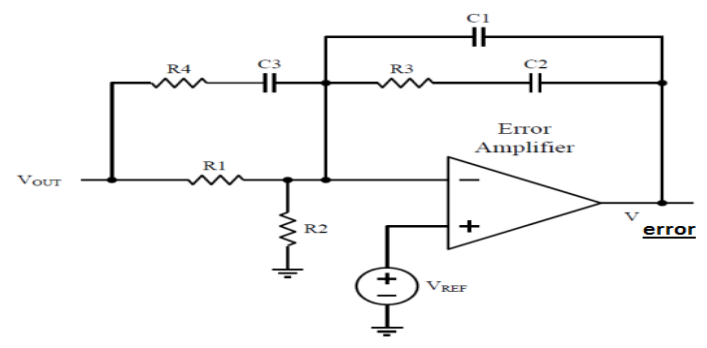

Figure.8 Type III Compensation

$$
\mathrm{H}(\mathrm{s})=-\frac{(1+s R 3 C 2)(1+s(R 1+R 4) C 3)}{s R 1(C 2+C 1)\left(1+s R 3\left(\frac{C 2 C 1}{C 2+C 1}\right)\right)(1+s R 4 C 3)}
$$

C.6) Design equations for Type III Compensator-

1. Cut of frequency

$$
\mathrm{F}_{0}=\frac{F_{s W}}{2}
$$

2. Frequency of poles

$$
\begin{aligned}
& \mathrm{F}_{\mathrm{p}(\mathrm{R} 3 \mathrm{C} 1)}=\frac{1}{2 \pi R 3 \mathrm{C} 1} \\
& \mathrm{~F}_{\mathrm{p}(\mathrm{R} 1 \mathrm{C} 2)}=0 \\
& \mathrm{~F}_{\mathrm{p}(\mathrm{R} 4 \mathrm{C} 3)}=\frac{1}{2 \pi R 4 \mathrm{C}_{3}} \\
& \mathrm{~F}_{\mathrm{p}\left(\mathrm{R} 4 \mathrm{C}_{3}\right)}=\mathrm{F}_{0} \sqrt{\frac{1-\sin (\theta)}{1+\sin (\theta)}}
\end{aligned}
$$

3. Frequency of Zeros-

$$
F_{Z(R 1 R 4 C 3)}=\frac{1}{2 \pi(R 1+R 4) C 3}
$$




$$
\mathrm{F}_{\mathrm{Z}(\mathrm{R} 3 \mathrm{C} 2)}=\frac{1}{2 \Pi r 3 \mathrm{C} 2}
$$

$$
F_{Z\left(R_{1 R 4} C_{3}\right)}=F_{0} \sqrt{\frac{1-\sin (\theta)}{1+\sin (\theta)}}
$$

$$
\mathrm{F}_{\mathrm{Z}\left(\mathrm{R} 3 \mathrm{C}_{2}\right)}=\frac{\mathrm{F}\left(\mathrm{R}_{1} \mathrm{R}_{4} \mathrm{C}_{3}\right)}{2}
$$

4. Main parameters-

$$
\begin{aligned}
& \mathrm{C} 1=\frac{1}{2 \pi \mathrm{R} 3 \mathrm{~F}_{\mathrm{P}(\mathrm{R} 3 \mathrm{C} 1)}} \\
& \mathrm{C} 2=\frac{1}{2 \pi \mathrm{R} 3 \mathrm{~F}_{\mathrm{Z}_{(\mathrm{R} 3 \mathrm{C} 2)}}} \\
& R 4=\frac{1}{2 \pi C 3 F_{P(R 4 C 3)}}
\end{aligned}
$$

\begin{tabular}{|c|c|}
\hline PARAMETER & VALUE \\
\hline$F_{0}$ & SOKHZ \\
\hline$F_{z\left(R^{2}\right)}$ & $15.9 \mathrm{Mhz}$ \\
\hline$F_{P(t C)}$ & $20 \mathrm{Khz}$ \\
\hline$F_{Z}(R: R u C 2)$ & 9Khz \\
\hline$\overline{F_{z} \text { (kacz) }}$ & $4.5 \mathrm{Khz}$ \\
\hline$F_{p(k a c 1)}$ & $150 \mathrm{Khz}$ \\
\hline$F_{P(R A C D)}$ & $284 \mathrm{Khz}$ \\
\hline $\mathrm{C1}$ & $132 \mathrm{pF}$ \\
\hline$c 2$ & $4.4 \mathrm{nF}$ \\
\hline $\mathrm{C3}$ & $1 \mathrm{nF}$ \\
\hline R1 & $18.23 \mathrm{k} \Omega$ \\
\hline$R 2$ & $126 \Omega$ \\
\hline R3 & $7.8 \mathrm{~K} \Omega$ \\
\hline$R 4$ & $280 \Omega$ \\
\hline
\end{tabular}

$$
R 1=\frac{1}{2 \pi C 3 F_{Z(R 1 R 4 C 3)}}-R 4
$$

$$
R 2=\frac{R 1 V_{\text {REF }}}{V_{\text {OUT }-V_{\text {REF }}}}
$$

Based on the above formulae, following values has been calculated.

Table.1 Design parameters

\section{Power Stage Components}

The following parameters are needed to calculate the power stage:

1.) Maximum switch current

2.) Inductor selection

3.) Capacitor selection

4.) Rectifier diode selection

5.) MOSFET selection

6.) Duty cycle

\section{Results and discussions}

Buck converter for portable applications has been designed with input voltage of 3 volts and desired output voltage is $1.5 \mathrm{v}$ with switching frequency of $300 \mathrm{khz}$. 
System level simulation has been carried out with Cadence P-spice in 0.30um technology and stability of buck converter with type III compensation has been investigated by Mat Lab tool, , phase margin for buck converter has been observed approximately 60deg which is best to ensure stability of buck converter. After calculating power losses in terms of conduction, switching, and others, optimum efficiency of design is $93 \%$.

A.)Design specification \& Output Table

This table defines all the parameters which are used to simulate the design

B.) Stability measure-

For above parameters calculated and defined stability of buck design has been verified with compensation and without compensation and it is observed that phase margin of design is approximate to 53 deg which shows that design is quite stable under load and ripple variations.

Table.2 Design specifications

\begin{tabular}{|c|c|c|}
\hline S.no & Parameter & Value \\
\hline 1 & $\operatorname{Vin}$ & $3 \mathrm{~V}$ \\
\hline 2 & V out & $1.4 \cdot 1.6 \mathrm{~V}$ \\
\hline 3 & Switching Inductor & $10 \mathrm{uH}$ \\
\hline 4 & Output Capacitor & $4.7 \mathrm{uF}$ \\
\hline 5 & Inductor DC Reststance & $3 \mathrm{~m}$ ohm \\
\hline 6 & $\begin{array}{l}\text { Capacitor Equivalent Series } \\
\text { Resistance }\end{array}$ & $2 \mathrm{mohm}$ \\
\hline 7 & Switching frequency & $300 \mathrm{Kh} z$ \\
\hline 8 & Reterence Voltage & $1.4 \mathrm{~V}$ \\
\hline 9 & Inductor Current Limit & $2 A$ \\
\hline 10 & Output Voltage Ripple & $0.75-1 \%(\mathrm{PP})$ \\
\hline 11 & Peak Rush in Current & $300 \mathrm{~mA}$ \\
\hline 12 & Peak Rush in Voltage & $1.8 \mathrm{~V}$ \\
\hline 13 & $\begin{array}{l}\text { Maximum Capacitor } \\
\text { Current }\end{array}$ & $60.120 \mathrm{~mA}^{-1}$ \\
\hline 14 & Steady State Voltage & $1.48 \mathrm{~V}$ \\
\hline 15 & Steady state Time & 90us \\
\hline 16 & Average Current & $200 \mathrm{~mA}$ \\
\hline 17 & Power Losses & $0.24 \mathrm{~W}$ \\
\hline 18 & $\begin{array}{l}\text { Synchronous Rectification } \\
\text { Efficiency }\end{array}$ & $92.6 \%$ \\
\hline
\end{tabular}

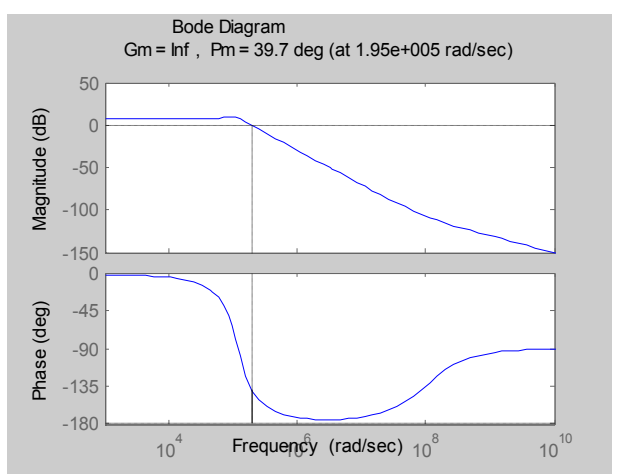

Figure.8 Bode Plot of Open Loop Converter

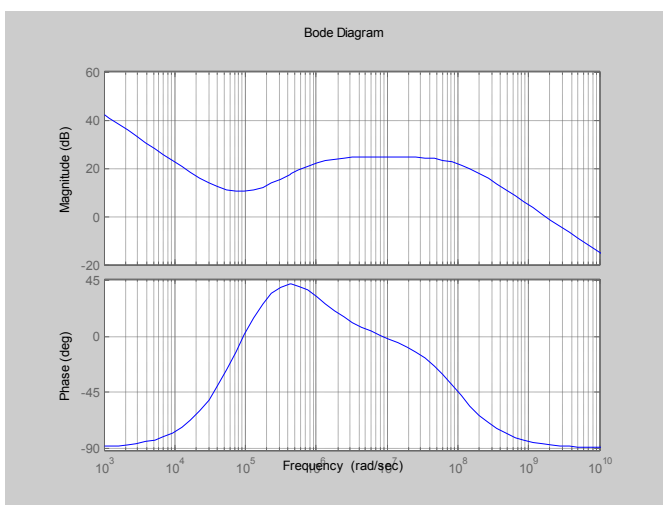

Figure.9 Bode Plot of Compensator 


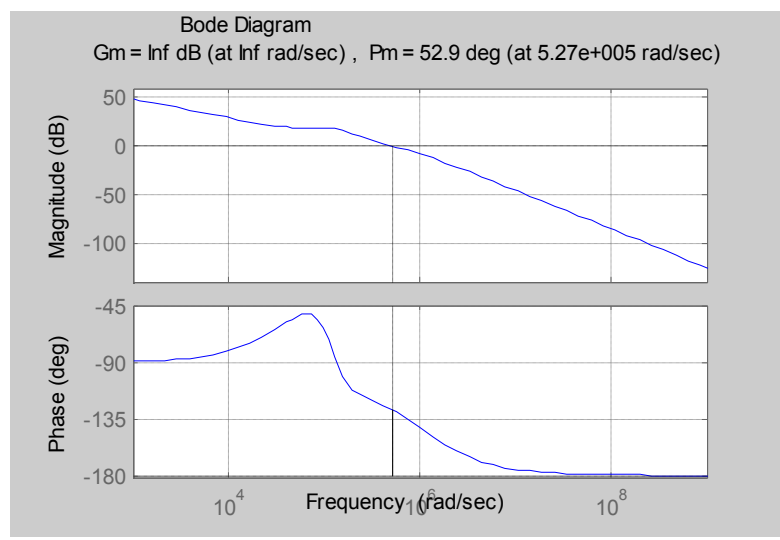

Figure.10 Bode Plot of Buck Converter

C.) Designs and Simulations-

C.1).Simple buck converter-

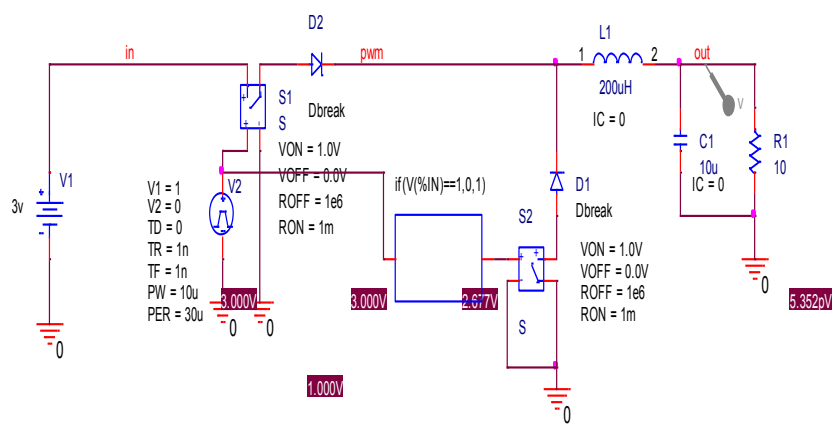

Figure.11 Simple Buck Converter design

C.2) Our design

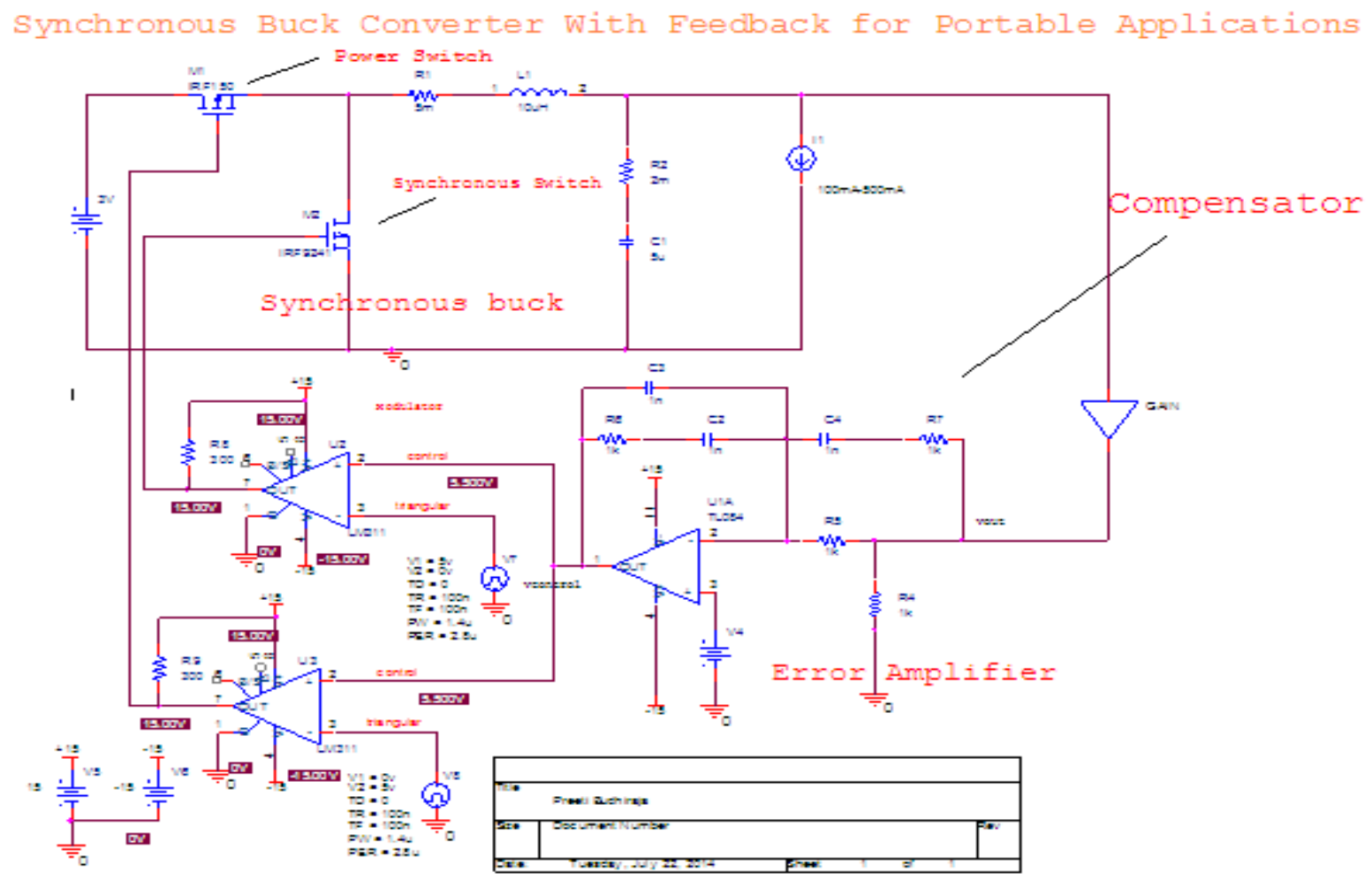

Figure.12 Proposed Buck Converter design 
C.3) Simulations-

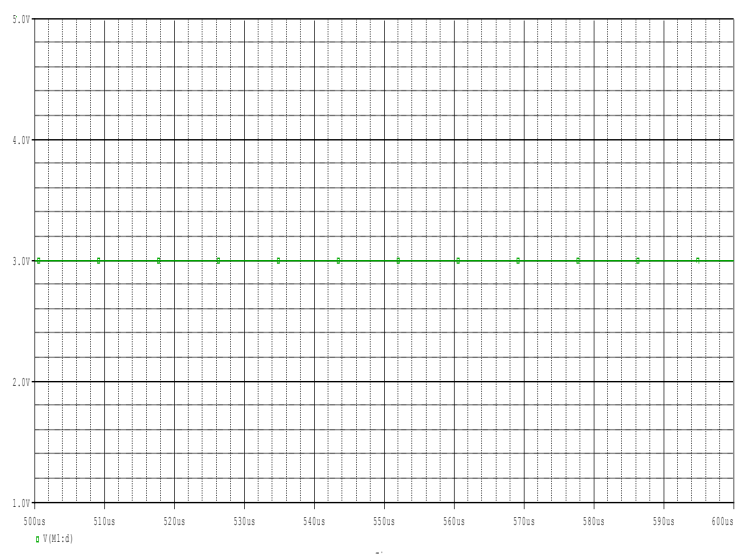

Figure.13 Input Voltage
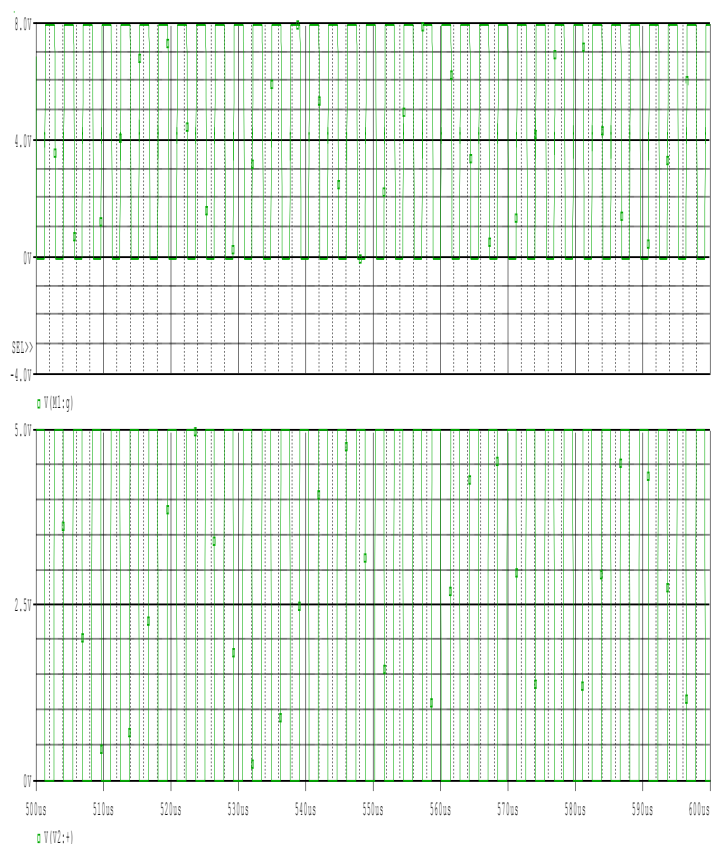
$07 \mid(\mid 2:+1)$

Figure.14 PWM Pulses

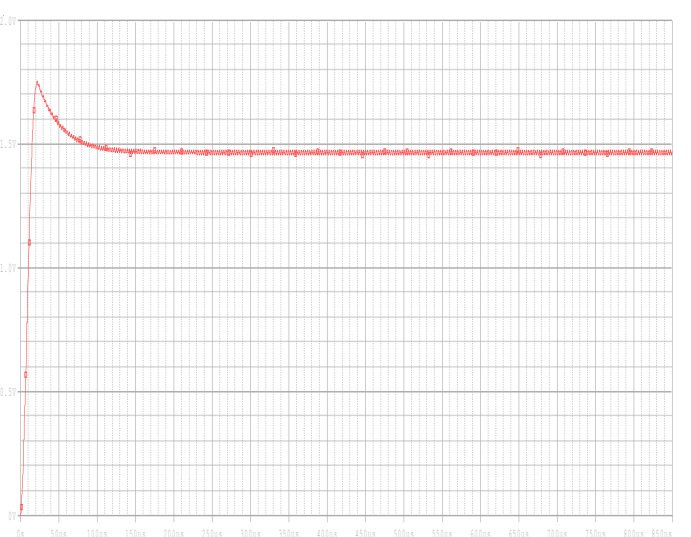

Figure.15 Output Voltage 


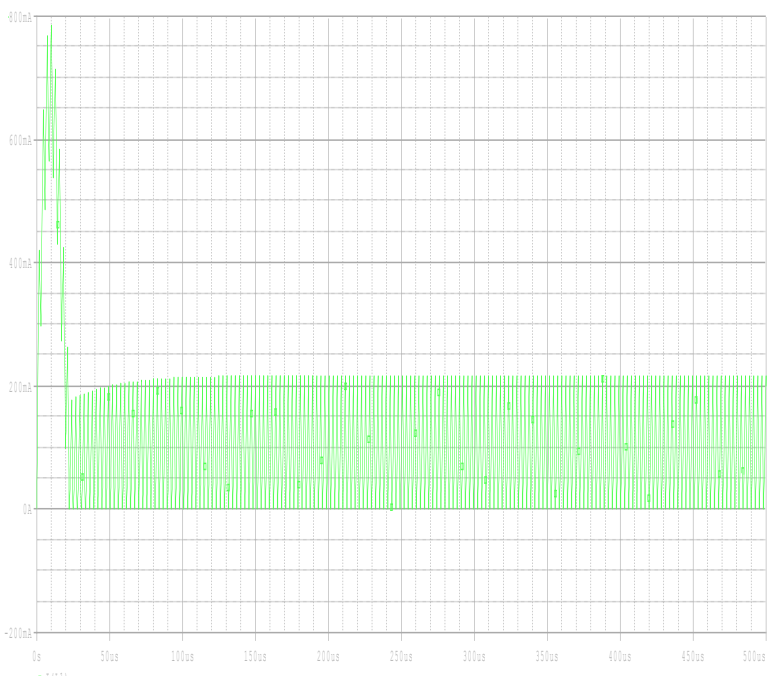

Figure.16 Peak Rush In Current

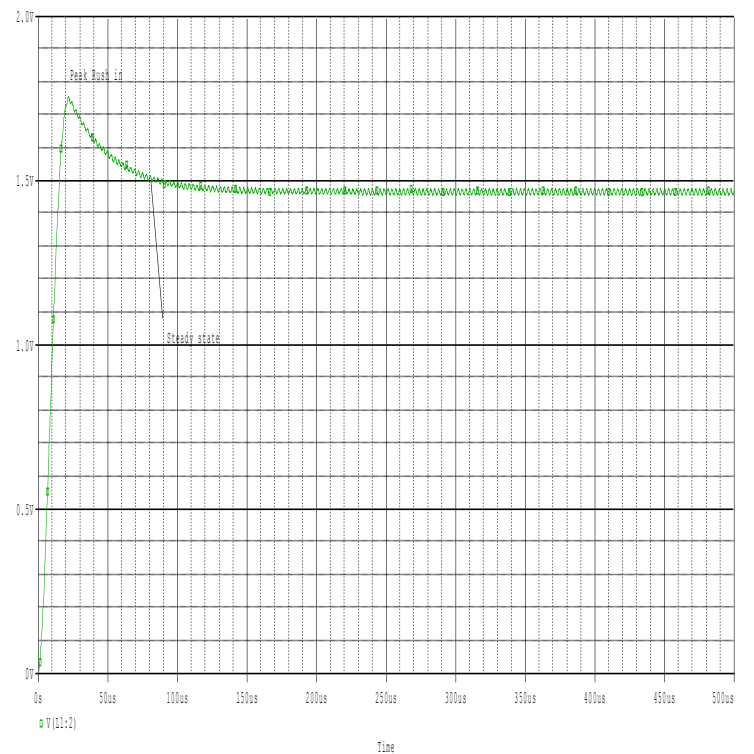

Figure.17 Steady State

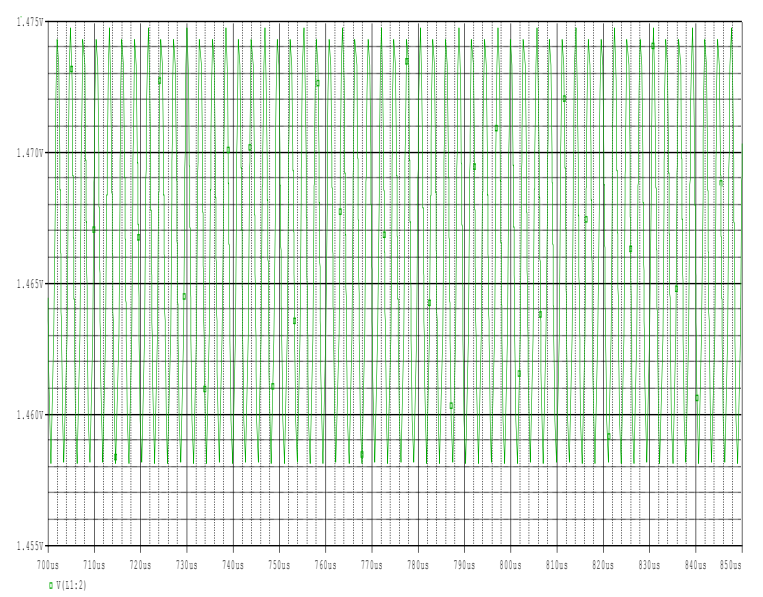

Figure.18 Output Voltage Ripple Peak to Peak (1VPP) 


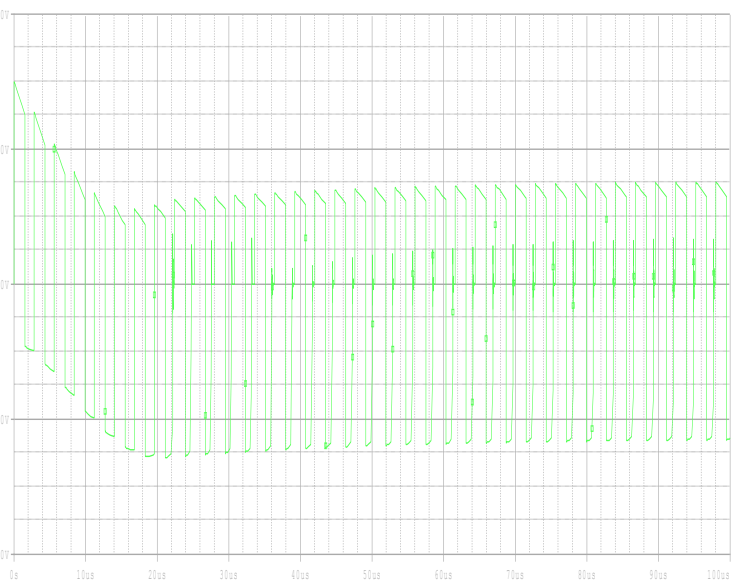

Figure.19 Differential Voltage across Inductor

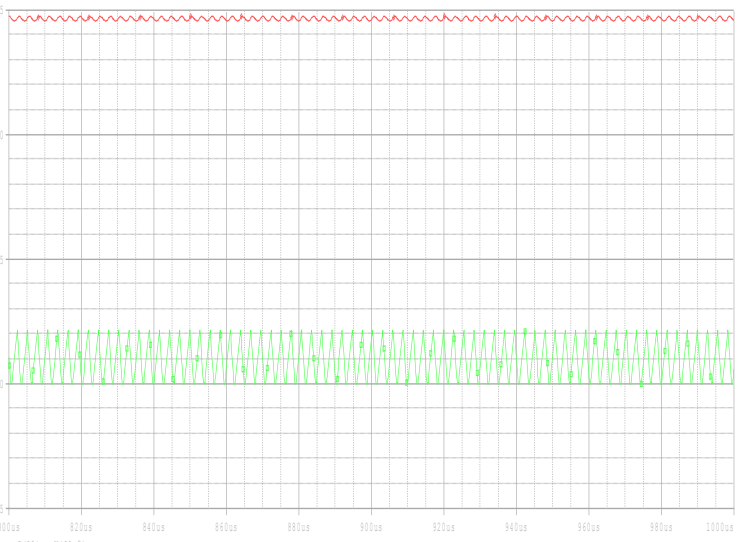

Figure.20 Dependency Of Continuous Conduction Current on output Ripple (decreases)

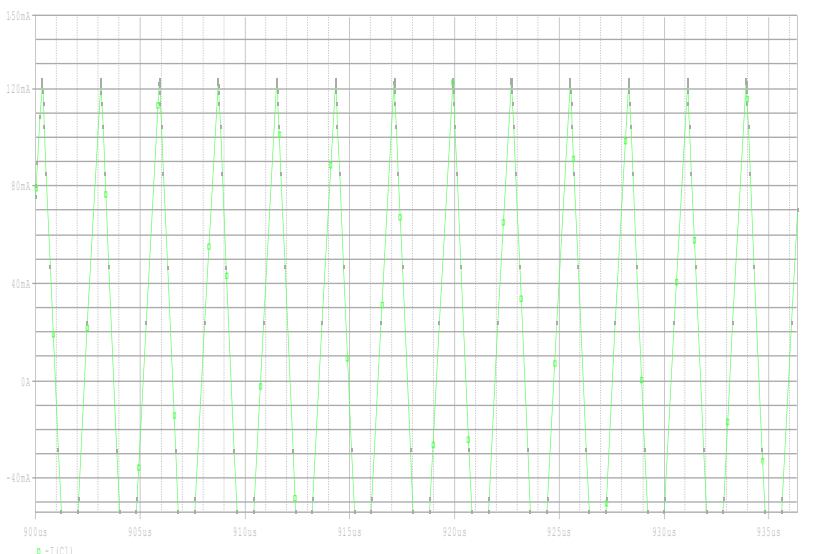

Figure.21 Current Through Capacitor 


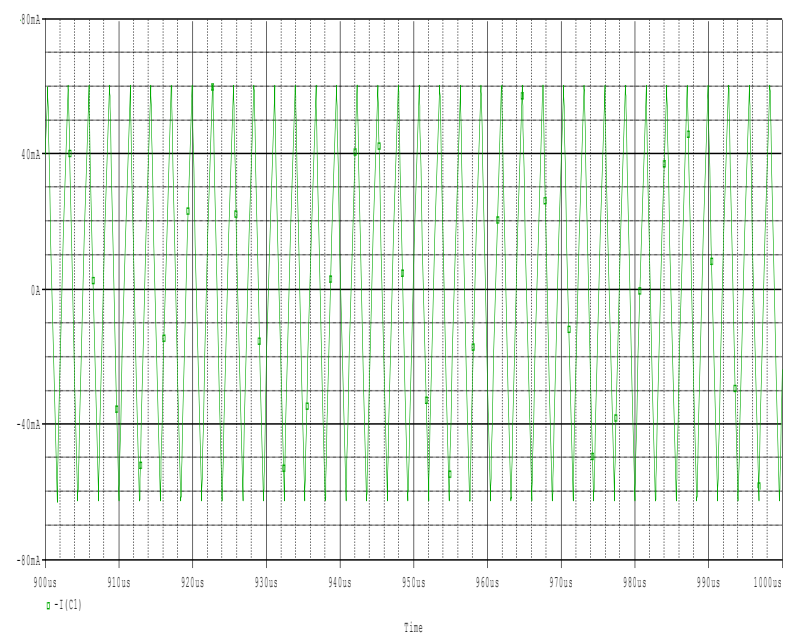

Figure.22 Peak current with ESR in series with capacitor

C.4) Observations

C.4.1)Effect of Load Variations on Efficiency-

The efficiency of the synchronous buck converter design with respect to load current is shown. The efficiency ranges from $80.8 \%$ to $92.7 \%$ at different loads.

\begin{tabular}{|c|c|c|}
\hline S. No & Load(mA) & Efficiency \\
\hline 1 & 100 & $92.7 \%$ \\
\hline 2 & 200 & $89.8 \%$ \\
\hline 3 & 300 & $86.4 \%$ \\
\hline 4 & 400 & $83.5 \%$ \\
\hline 5 & 500 & $80.8 \%$ \\
\hline
\end{tabular}

Table.3 Efficiency vs. Load

C.4.2) Effect of Load Variations on Output voltage ripple

Figure shows change of ripple in accordance with load a temperature-Nominal 27 Degree.

\begin{tabular}{|c|c|c|}
\hline S. No & I (load) & Output Voltage ripple \\
\hline 1 & $100 \mathrm{~mA}$ & $16.24 \mathrm{mV}$ \\
\hline 2 & $200 \mathrm{~mA}$ & $14.97 \mathrm{mV}$ \\
\hline 3 & $300 \mathrm{~mA}$ & $13.20 \mathrm{mV}$ \\
\hline 4 & $400 \mathrm{~mA}$ & $12.10 \mathrm{mV}$ \\
\hline 5 & $500 \mathrm{~mA}$ & $11.02 \mathrm{mV}$ \\
\hline
\end{tabular}

Table.4 Ripple vs. Load

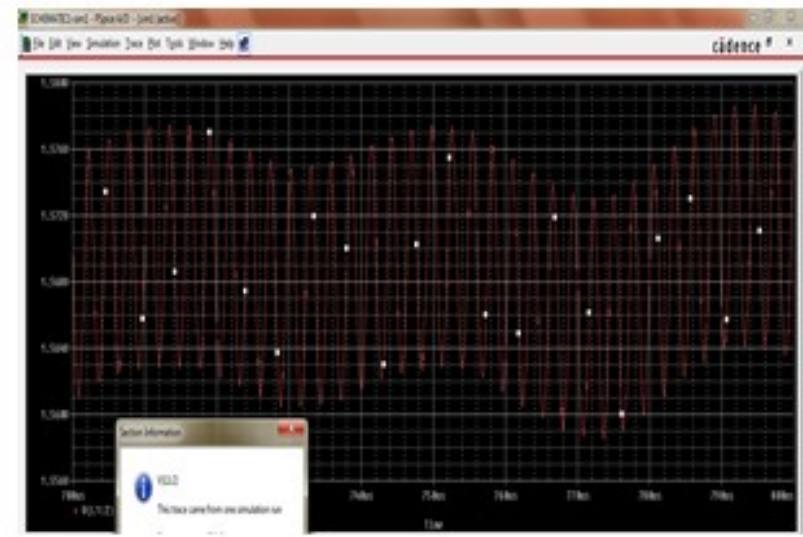

Figure.23 variations of ripple with load of $100 \mathrm{~mA}$ at $27 \mathrm{deg}$ 


\section{C4.3.Effect of Load Variations on Output Current ripple}

\begin{tabular}{|c|c|c|}
\hline S. No & I(load) & $\begin{array}{c}\text { Inductor Peak to Peak } \\
\text { current }(\mathrm{mA})\end{array}$ \\
\hline 1 & $100 \mathrm{~mA}$ & $200 \mathrm{~mA}$ \\
\hline 2 & $200 \mathrm{~mA}$ & $182.7 \mathrm{~mA}$ \\
\hline 3 & $300 \mathrm{~mA}$ & $171.8 \mathrm{~mA}$ \\
\hline 4 & $400 \mathrm{~mA}$ & $162.0 \mathrm{~mA}$ \\
\hline 5 & $500 \mathrm{~mA}$ & $148.4 \mathrm{~mA}$ \\
\hline
\end{tabular}

Table.5 Inductor current vs. Load

Table 6 compares the performance of the proposed converter with previous works. The proposed converter features the widest load current range, while maintain a high efficiency over the entire load region.

\begin{tabular}{|l|l|l|l|l|l|}
\hline & This work & Ref.1 & Ref.2 & Ref.3 & Ref.4 \\
\hline Parameter & $130 \mathrm{~nm}$ & $450 \mathrm{~nm}$ & $350 \mathrm{~nm}$ & $350 \mathrm{~nm}$ & $350 \mathrm{~nm}$ \\
\hline Input Voltage(V) & 3 & 3.3 & 1.8 & 3 & 5 \\
\hline Output Voltage & 1.5 & 2.9 & 1.2 & 1.65 & $>1$ \\
\hline Switching freq. & $300 \mathrm{khz}$ & $1 \mathrm{MHz}$ & $1.5 \mathrm{Mhz}$ & $1 \mathrm{Mhz}$ & $0.6 \mathrm{Mhz}$ \\
\hline Load Range(mA) & $100-500$ & $0.1-1000$ & $0.5-100$ & $0.1-500$ & $<460$ \\
\hline Efficiency (\%) & 93 & $79-91$ & $<87.2$ & $85-90$ & $<95$ \\
\hline Output Voltage ripple(mV) & $<20$ & $<41$ & $\begin{array}{l}\text { Not } \\
\text { Mentioned }\end{array}$ & $<35$ & $<36$ \\
\hline
\end{tabular}

Table.6 Comparison Between Previous Works

\section{Conclusion}

An efficient synchronous buck DC-DC converter which Includes PWM is presented. With a mode controller, the converter dynamically adjusts its work mode according to the load current varying condition. and Type III compensation is used by the converter to improve the load capability. The system level simulations has been carried out under a standard 130nm CMOS technology. In a load range between 100-500 mA, the efficiency could achieve $85 \%-93 \%$.

\section{References}

[1]. Bandyopadhyay S, Ramadass Y K, Chandrakasan A P. 20 uA to $100 \mathrm{~mA}$ DC-DC converter with 2.8-4.2 V battery supply for portable application. IEEE J Solid-State Circuits, 2011, 46(12): 2807

[2]. Huang H W, Chen K H, Kuo S Y. Dithering skip modulation, width and dead time controllers in highly efficient DC-DC converters for system-on-chip applications. IEEE J Solid-State Circuits, 2007, 42(11): 2451

[3]. Liou W R, Yeh M L, Kuo Y L. A high efficiency dual-mode buck converter IC for portable applications. IEEE Trans Power Electron,2008, 23(2): 667.

[4]. Jinwen Xiao, Angel Peterchev, Jianhui, Seth Sanders, “An Ultra-Low-Power Digitally-Controlled Buck Converter IC for Cellular Phone Applications", Applied Power Electronics Conference and Exposition, 2004. Nineteenth Annual IEEE, Volume 1, Issue, 2004 Page(s): 383 - 391 Vol.1

[5]. Chin Chang, "Robust Control of DC-DC Converters: The Buck Converter", Power Electronics Specialists Conference, 1995. 26th Annual IEEE Volume 2, Issue , 18-22 Jun 1995 Page(s):1094 - 1097 vol.2

[6]. Mika Sippola and Raimo Sepponen, "DC/DC Converter technology for distributed telecom and microprocessor power systems - a literature review", Helsinki University of Technology Applied Electronics Laboratory, Series E: Electronic Publications E 3, 2002

[7]. Chang, C., "Mixed Voltage/Current Mode Control of PWM Synchronous Buck Converter", Power Electronics and Motion Control Conference, 2004. IPEMC 2004. The 4th International, Publication Date: 14-16 Aug. 2004, Volume: 3, On page(s): 1136- 1139 Vol.3

[8]. G. Belverde, C. Guastella, M. Melito and S. Musumeci, R. Pagano, A. Raciti, "Advanced Characterization of Low-Voltage PowerMOSFETs in Synchronous-RectifierBuck-Converter Applications"

[9]. Stradale Primosole, 50 - 95121-Catania, Italy pages(1802-1809))( 2003 IEEE

[10]. Ned Mohan, Tore M. Undeland, William P. Robbins, "Power Electronics: Converters, Applications, and Design", $3^{\text {rd }}$ Edition, Wiley

[11]. B. J. Baliga, "Modern Power Devices”, New York: Wiley, 1987.

[12]. http://powerelectronics.com

[13]. http://powerelectronics.com $/$ mag/power_buck_converter_losses/index.html 